Article

\title{
The Influence of the Environment on the Patient- Centered Therapeutic Relationship in Physical Therapy: A Qualitative Study
}

\author{
Jaume Morera-Balaguer1, Mari Carmen Martínez-González², Sonia del Río-Medina³, Víctor

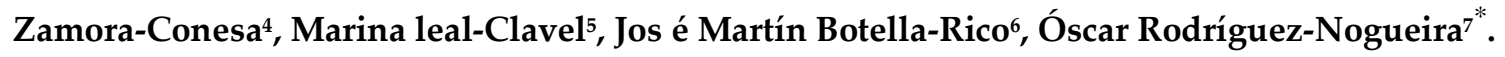 \\ ${ }^{1}$ Universidad Cardenal Herrera-CEU, CEU Universities, Physical Therapy Department, Plaza Reyes \\ Católicos, Elche, Alicante, Spain; e-mail: jmorera.el@uchceu.es \\ 2 Universidad Cardenal Herrera-CEU, CEU Universities, Medicine Department, Plaza Reyes Católicos, Elche, \\ Alicante, Spain; e-mail: mcmartinez@uchceu.es \\ ${ }^{3}$ Universidad Cardenal Herrera-CEU, CEU Universities, Physical Therapy Department, Plaza Reyes \\ Católicos, Elche, Alicante, Spain; e-mail: Sonia.rio@uchceu.es \\ ${ }^{4}$ Universidad Cardenal Herrera-CEU, CEU Universities, Physical Therapy Department, Plaza Reyes \\ Católicos, Elche, Alicante, Spain; e-mail: victor.zamora@uchceu.es \\ ${ }^{5}$ Universidad Cardenal Herrera-CEU, CEU Universities, Nursing Department, Plaza Reyes Católicos, Elche, \\ Alicante, Spain; e.mail: mleal.el@uchceu.es \\ ${ }^{6}$ Universidad Cardenal Herrera-CEU, CEU Universities, Physical Therapy Department, Plaza Reyes \\ Católicos, Elche, Alicante, Spain; e-mail: jmbotella@uchceu.es \\ 7University of León, Health Sciences School, Nursing and Physical Therapy Department, Ponferrada León, \\ Spain; oscar_sonrie@hotmail.com \\ * Correspondence: oscar_sonrie@hotmail.com
}

\begin{abstract}
Currently, in the scientific literature there is a great interest on the study of strategies to implement patient-centered care. One of the main tools for this is the therapeutic relationship. Some studies suggest that the perception of the environment in which the physical therapy treatment takes place can influence the perception of its quality. A qualitative study using focus groups was performed. Two researchers conducted the focus groups, using a topic guide with predetermined questions. The focus group discussions were audio-recorded, transcribed verbatim and analyzed thematically using a modified grounded theory approach. The setting was three hospitals and six public health centers located in Spain. The inclusion criteria were patients who had received a minimum of 15 physical therapy sessions and with no communication impairments. Thirty-one participants in four focus groups. Participants described a series of specific experiences relating to the environment, which they felt were influential in the establishment of therapeutic patientcentered relationships, including eight physical factors and five organizational factors. The results of this study highlight environmental factors that affect the quality of the therapeutic patientcentered relationship in physical therapy and emphasize the need for physical therapists and administrators to rethink the situation and propose strategies for improvement.
\end{abstract}

Keywords: patient centered care; physical therapy; professional-patient relations; therapeutic relationship; environment. 


\section{Introduction}

Currently there is a great interest in studying strategies to implement patient-centered care (PCC) in all areas of healthcare [1-7]. According to Morgan and Yoder [8], PCC is a "holistic (biopsycho-social-spiritual) approach to delivering care that is respectful and individualized, allowing negotiation of care, and offering choice through a therapeutic relationship where persons are empowered to participate in health decisions at whatever level is desired". This model has been recommended by several prestigious professional organizations, such as the Institute of Medicine (IOM) and others [9-13] as a way to increase the quality of health care.

One of the most relevant factors for the establishment of PCC is the quality of the therapeutic relationship, or the relationship that is established between the care providers and their patients [613]. There is growing consensus that the quality of care depends directly on communication and the relationship between patient and therapist, both in the field of physical therapy $[4,5,14-19]$ and in others [20].

Several authors have demonstrated the relationship between aspects of the environment in which the service is provided and certain relevant indicators. Factors such as the location of the treatment center, the parking facilities used to access the center, the waiting time to receive therapy[21], or certain elements of the physical environment (e.g., cleanliness, privacy) have been related to the quality and satisfaction perceived by the patient in rehabilitation settings [22,23] .

Furthermore, the importance of the environment is being widely studied in marketing and environmental psychology. These two disciplines recognize that certain socio-environmental factors can influence the perceptions of service quality. Marketing literature recognizes the relevance of three specific service attributes of the physical environment: design, environmental conditions and social factors [24]. From the perspective of environmental psychology, there is a broad line of research on the influence of these factors on variables such as environmental stress, environmental overload and deprivation, psychophysiological and behavioral effects, and performance [25].

Nonetheless, limited research has been conducted on the possible influence of the environment where treatment is administered and the perception of the quality of the therapeutic relationship between patient and professional. In a previous study [26,27], we found that some environmental aspects may act as barriers or facilitators for the establishment of a patient-centered Therapeutic Relationship. We therefore consider that environmental factors can influence the establishment and perception of the patient centered Therapeutic Relationship in physical therapy.

This research is part of a wider study attempting to perform an in depth analysis of the perceptions and experiences of patients and physical therapists that influence the perceived quality of the patient-centered therapeutic relationship in physical therapy. This study aimed to understand the influence of the environment in which physical therapy treatment takes place on the patients' perception of the quality of the patient-centered therapeutic relationship in public health centers in Spain. To this end, this study explores the experiences and perceptions of patients regarding this aspect.

\section{Experimental Section}

\subsection{Study design}

A qualitative study was conducted based on the use of focus groups. Focus groups have been used previously to identify experiences related to how health services are perceived [23,28]. 


\subsection{Scope and participants}

The inclusion criteria consisted of patients from physical therapy units in primary care and public hospitals in Spain with a minimum of 15 treatment sessions [28]. The sole criterion for exclusion was the existence of any type of cognitive or communication disability.

\subsection{Recruitment}

Patients were recruited from three hospitals and six primary care centers. The recruitment was carried out by the same physical therapists who were treating the patients, who volunteered after a meeting with a member of the research team, in which they explained the objectives of the project and their participation. Each physical therapist reviewed their list of patients to identify those who met the selection criteria, drawing a list of possible participants.

The researchers made a selection of the profiles using intentional sampling to obtain a heterogeneous sample and to explore the phenomenon under study with sufficient breadth and depth[29]. An attempt was made to include subjects with different profiles considering the sociodemographic characteristics that in previous studies have been shown to influence perceptions of the quality of the therapeutic relationship[30]: patients from rural and urban areas, from hospitals and primary care centers, of different ages, sex and pathologies. Figure 1 presents a scheme of the stages of selection process.

Figure 1. Stages of selection process for focus groups

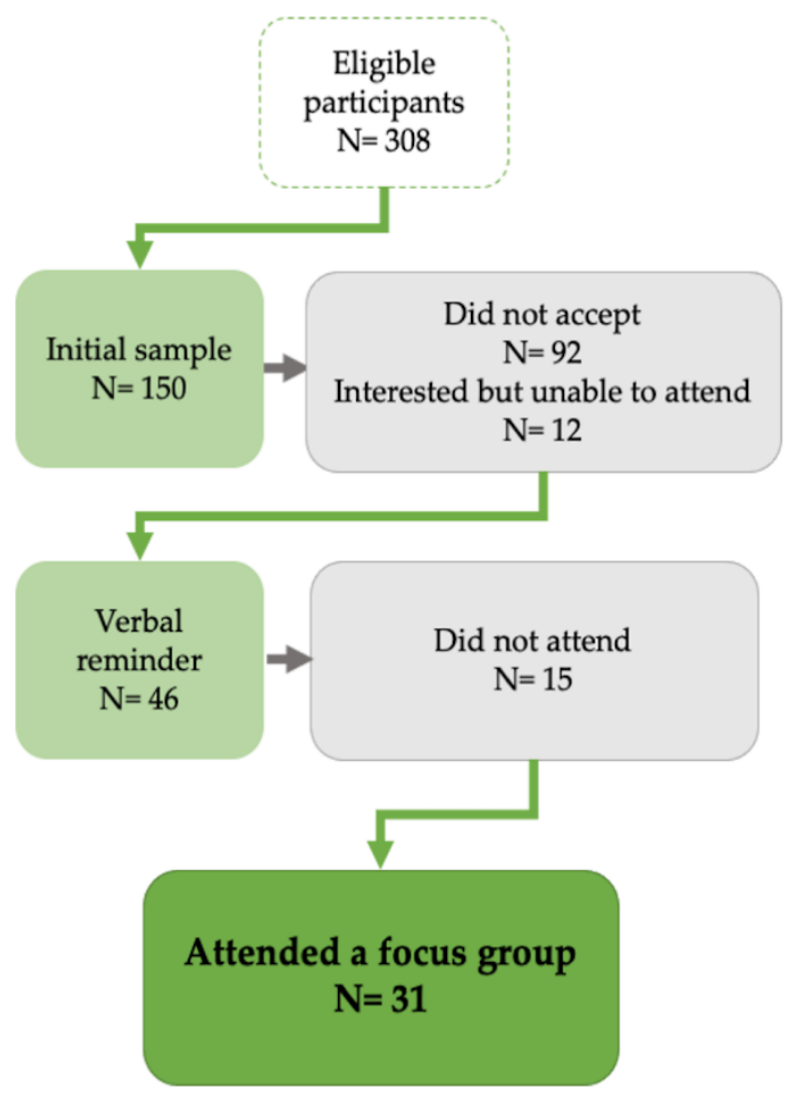




\subsection{Ethics}

The study was approved by the Research Ethics Committee of the Cardenal Herrera CEU University and the Ethics and Research Committees of the General University Hospital of Elche, the Vinalopó Hospital, and the Provincial Hospital of Valencia.

\subsection{Data collection}

All focus groups were led by a moderator (JMB) and an assistant (ORN). All sessions were held in a room that was separate from the care center (community centers run by associations and institutions) with the aim of creating an appropriate environment for discussion, away from the clinical context of physical therapy care units. A topic guide with predetermined questions was created and used based on a literature review (Table 1). Group discussions were audio and video recorded. Focus groups were held until data saturation was achieved, meaning that no new categories emerged after analysis of the previous focus group data [31].

Table 1. Patient focus group questions guide

1. What do you most value about the physical therapist?

2. What did you like the most about your relationship with the physical therapist?

2.1 In which situations have you felt most comfortable with the physical therapist?

\subsection{In which situations have you felt uncomfortable with the physical therapist?}

2.3 Did the physical therapist appear the way he/she genuinely is? (the physical therapist was able to show his/her limitations, recognize errors, be natural...)

3. Which attitudes or behaviors of the physical therapist make you trust him/her?

4. When do you tend to talk with the physical therapist?

5. What do you tend to talk to the physical therapist about?

6. Have you felt understood and supported during treatment?

7. Do you believe the physical therapist sought your collaboration during treatment? 7.1 In order to establish objectives

\subsection{In order to establish the means for achieving these objectives}

8. Do you believe the physical therapist gives you all the information you need to know?

9. Do you tend to understand the physical therapist? Yes, no; when? and why?

10. How do you describe the environment in which your relationship with the physical therapist takes place? And, how does this environment affect you?

11. What aspects do you consider are worth improving in the relationship between the physical therapist and yourself? 


\subsection{Analysis}

The sessions were transcribed verbatim (VZC, SRM) for independent analysis. The names of the participants were anonymized using a numerical code assigned for the transcripts and quotations. A modified constant comparison methodology was used for data analysis [44,45]. Three authors (JMB, ORN, MCMG) independently reviewed the transcripts and coded sentences containing significant units of analysis. These were grouped into categories using a combination of emerging codes. The same three authors reviewed and compared their findings to reach agreement on codes and categories. Three rounds of coding and discussion were conducted with the aim of improving the reliability of the coding process and developing clearer categories. This process was iterative with the collection of data from subsequent transcripts.

The next level of analysis sought to identify the relationships between categories and the grouping of categories with hierarchical conceptual uniformity in themes and sub-themes. To evaluate the consistency of the final topics and subtopics, two researchers (SRM, VZC) verified their agreements based on a blind review using codes for the same passages from two transcripts [32]. Any disagreement between the two researchers was resolved by discussion. At each step, an independent author (MCMG) played the role of reviewer to verify whether the analysis was systematically supported by the data, with the intention of enhancing dependability [33].

\section{Results}

Four focus groups were held until information saturation was reached. The size of the focus groups ranged from six to nine participants. In total, 31 patients participated in these focus groups. The characteristics of the participating patients are shown in Table 2.

Table 2. Characteristics of the participants in the focus groups.

\begin{tabular}{|l|l|}
\hline Characteristics & $\mathbf{n}(\%)$ \\
\hline Gender & $21(67.74)$ \\
\hline Female & $10(32.26)$ \\
\hline Male & 52.71 \\
\hline Mean & 14.93 \\
\hline SD & \\
\hline Treatment time (weeks) & 27 \\
\hline Mean & 76.86 \\
\hline SD & \\
\hline Level of studies & $19(61.29)$ \\
\hline No studies & $10(32.25)$ \\
\hline Secondary & $2(6.46)$ \\
\hline University studies & \\
\hline Pathology & $21(67.74)$ \\
\hline Musculoskeletal & $10(32.26)$ \\
\hline Neurological & \\
\hline
\end{tabular}


The participants' experience was related to one of the following topics: physical characteristics, and organizational characteristics. Figure 2 shows the final summary of topics and categories, following a hierarchy that was defined by the level of abstraction.

Figure 2. Outline of themes, subthemes and categories.

Patients' perceptions of the influence of the environment on the quality of the therapeutic relationship with physical therapists
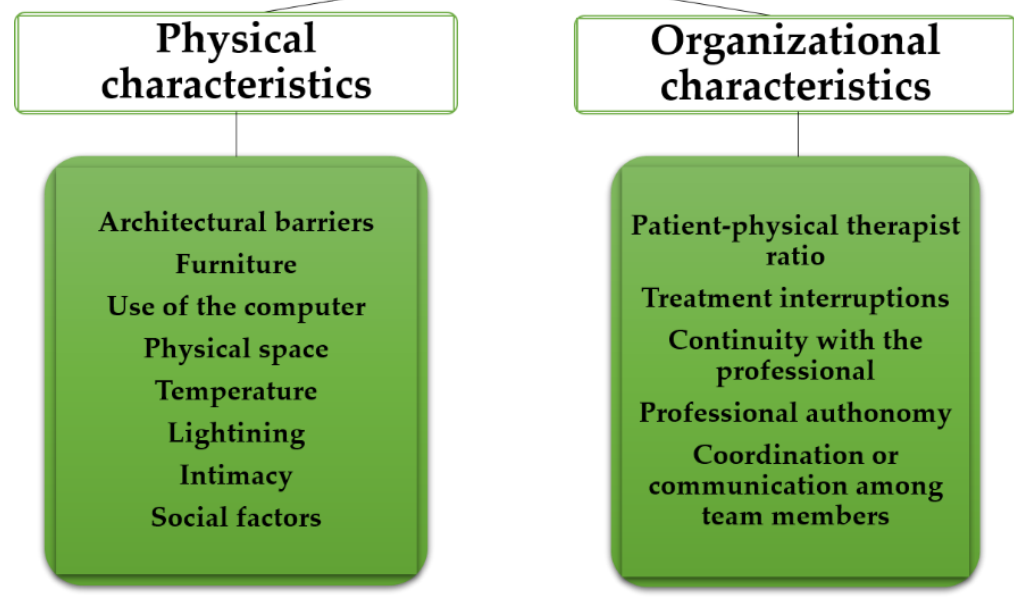

In the text below, the developed categories are presented, accompanied by quotes from the participants.

\subsection{Physical characteristics}

Many participants discussed the negative influence of architectural barriers in their relationship with their physical therapist. For example, the presence of columns may hinder visibility between the patient and physical therapist. Several patients also described the inconvenience of having the physical therapist's office separate from the treatment room. For example, one patient stated:

Also, the architectural barriers that the room has because here is the rehabilitation room, a sink, a dressing room, the office and a room for electrotherapy. So of course, if they go into the office you can't communicate with them...(Vicente, 48 years old, polytraumatized, 40 sessions).

Some patients told us that at times unsuitable furniture can make it difficult to establish a rapport of trust, and can also hamper communication between the physical therapist and the patient. For example, one patient spoke of the feeling of distrust caused by the existence of a table between the doctor and the patient, compared to the situation when she is in with the physical therapist:

Yes, they don't have the table either... they have their chair, which goes up and down and you have your chair, you know, which gives you the feeling that you are talking to the president of the company [with the doctor] ... whereas the physio is next to you, or in front of you... there is no barrier. (Janet, 68 years old, cervicalgia, 22 sessions)

Similarly, several patients told us about the difficulty of establishing fluid communication due to the use of the computer:

The treatment with her, great, very kind, she worries about everything, tries to be on top of everything, but when she goes into the office she has to keep a file there on who has come, who hasn't shown up...yes, the 
computer issue blocks them a lot...it makes communication difficult. (woman, 27 years old, anterior cruciate ligament reconstruction, 20 sessions).

Several patients told us about the problems generated by a physical space that was neglected, poorly maintained or too small for the establishment of a good relationship with their physical therapist, as this could result in difficulty in establishing a relationship of trust with their physical therapist. According to one patient:

... and you see yourself in classrooms that measure 40 meters, where there are 20,000 machines, and often you have to do exercises that you can't do...then the floor is very bad...the tile moves, there's a cracked tile...you feel like you're being treated very poorly. (Man, 63 years old, traumatic brain injury, 40 sessions).

Some patients talked about the effect on their mood of some less tangible aspects of the space in which the treatment was performed, such as the temperature:

The barracks they have for rehabilitation are a scandal. I was doing cardiac rehab. Apart from the fact that it was unbearably hot... it is third worldly, it doesn't make you want to do anything. (Man, 58 years old. Heart attack, 20 sessions).

Also, the lighting was considered important:

We're in a kind of den where there are no windows, when the light is a little dim it seems like a storm is raging...the lighting is also important, and here it's all kind of aseptic, it's like a prison or something. (Woman, 45 years old, Colles' fracture, 22 sessions).

Another factor commented on by many patients was the need for intimacy. According to the participants, there is a lack of intimacy in the spaces where the physical therapy treatment is carried out in public centers, which prevents patients from finding moments to talk to their physical therapist about delicate matters, making communication and the establishment of trust difficult. According to one of the participants:

...because if their doing something to you and it hurts, you want your moment, your space, and to be able to talk to the physical therapist... at that moment I would have said, "go on," but I would have cried because I wouldn't have had people looking at me. (Woman, 73 years old, knee prosthesis, 30 sessions).

Additionally, social factors present in the treatment space, such as the number of patients or interactions between them, were relevant to the patients. This could determine the perception of a relaxed environment, conducive to relationships. For example, some participants told us that sharing space with others who were in the same situation or similar to their own encouraged them and made them more eager to come to treatment:

As for me, I liked the fact that people were close by, that they chatted and so on, because maybe you went there with a bad feeling, and the other person who was there also gave you a hand and so on. (Man, 78 years old, fibromyalgia, 40 sessions).

\subsection{Organizational characteristics}

Many patients complained that the patient-physical therapist ratio was too high. According to these patients, this became a problem for establishing a good relationship with their physical therapist because they had very limited time to work with them.

...he can't attend each person individually, and the personal treatment with the physio is what you get over time because there are people who are going to do 10 sessions and practically don't become acquainted with him. (Woman, 22 years old, fractured tibia and fibula, 25 sessions). 
These time constraints meant that sometimes the physical therapist was unable to fully focus on the patient he/she was treating:

He is doing something to you but at the same time he is watching someone else, and so he is not $100 \%$ focused on what he is doing. (Man, 40 years old, shoulder surgery, 28 sessions).

Another common complaint were interruptions in the middle of treatment. This was often due to the saturation caused by the patient-physical therapist ratio being too high, and the patients themselves understood this. However, this prevented effective and fluid communication, and the establishment of the necessary trust between the physical therapist and the patient:

It makes me a little stressed to know that she has very little time, as soon as she approaches you have to say "" me, me "", and that doesn't make you feel relaxed, I don't think it's professional, I know she's professional but the conditions don't make her professional. I think we all deserve individualized quality treatment, not having to beg for it". (Woman, 59 years old, low back pain, 18 sessions).

Many patients explained that the lack of continuity with the same professional made it difficult to create a flow of communication, which hampered the establishment of a therapeutic relationship:

If that person has connected with you, and has given you positive vibes...and encourages you, and stimulates you and you function well, switching to someone else... you have to start again from scratch, and if you don't connect so much, it's like a colder environment in rehab. (Man, 60 years old, multiple sclerosis, 80 sessions).

Many participants perceived that the physical therapist had a lack of professional autonomy, which in turn had a negative influence on the establishment of trust towards the professional. According to one patient:

... because, often, the physio should work more individually and does not do so because the guidelines that the doctor has set are such and such. And the physio says "no, I can't touch you because I've been told that I can't do this. I should do it, but I can't, since I have not been told to do it," and in the end you don't know who to trust. (Man, 52 years old, scapulohumeral periarthritis, 38 sessions).

Another frequent comment among participants was the perception of a lack of coordination or communication among team members, which caused patients to end up distrusting the people who treated them. One patient reported:

... when it comes to the person who has worked with me, great, the big problem is the contact between the doctor who sends you, the physical therapist, and the patient, that's the problem. (Woman, 46 years old, fibromyalgia, 30 sessions).

Some patients also perceived contradictory information at times between professionals of the rehabilitation team and other departments, such as traumatology, which made them lose their confidence in the professionals and in the system in general:

The physio told me that he was going to give me another treatment, and he told me that if it doesn't get better they will have to operate on me, and the traumatologist said both times I went in that they would either infiltrate or operate. (Woman, 48 years old, supraspinatus tendinitis, 20 sessions).

\section{Discussion}

The results of this study show that the patient's perception of the quality of the therapeutic relationship established with their physical therapist depends, in part, on their experiences with the physical and organizational environment of the institution where they receive physical therapy treatment. Our findings support the results found in previous studies that relate patients' experiences 
with the environment and other constructs close to the patient-centered therapeutic relationship, such as perceived quality [34], patient satisfaction [35-38], or clinical outcomes [39-41]. We were unable to find studies that directly relate the environment to the therapeutic relationship, however, as shown above, these three indicators are related to this construct.

Our study demonstrated that there are two areas of focus in patients' perceptions of the environment: physical characteristics, and organizational characteristics. Brady and Cronin, in 2001 [24], demonstrated that the perceived quality of any service is formed on the basis of three primary dimensions of the service: the interaction between user and provider, the physical environment in which the service is provided, and the results obtained. In their hierarchical model of perceived quality, each dimension is in turn formed by several sub-dimensions. The physical environment dimension is formed by: environmental conditions, design, social factors and waiting time. The first two sub-dimensions correspond to the area we have called Physical Characteristics, while the Social Factors sub-dimension corresponds to Organizational Characteristics.

Medina i Mirapeix et al, in a study [23] which sought to understand how the service environment influences patients' perception of service quality, identified two main areas: the physical environment and the organizational environment. Within the physical environment, the following were highlighted: the design of the facilities, regarding the need for intimacy, and the architectural design and the therapeutic and non-therapeutic equipment; environmental conditions were also mentioned, including non-visual aspects such as the smell and the room temperature of the space; also, social factors, such as the number of people in the space and the relationships among other patients and therapists. Concerning the organizational environment, patients reported that the duration of the therapist's treatment (which they considered to be determined by the conditions of the client/physical therapist ratio), the interruptions that occurred during treatment, the time spent waiting for different treatment modalities during the same session, and the patient's safety (related to the need for the therapist to be always aware of the patient during treatment, and which is dependent on the client/physical therapist ratio) were considered important.

O'Keeffe et al found that patients were dissatisfied with the care received when they perceived organizational failures affecting waiting time or appointments [42]. In turn, Oosterhof et al [43] revealed that, according to patients in their study, canceled appointments, professional untimeliness, and changes in the treatment program that were not adequately implemented or explained made interactions and outcomes difficult. In our study no such claims were found, however, some of the participants' perceptions (the importance of social factors, of the client-physical therapist ratio, intimacy, interruptions during treatment, the perception of lack of autonomy on behalf of the physical therapist or the poor coordination or communication between the team of professionals) are directly related to these outcomes.

Harrison et al[44], conducted a study with patients and physical therapists and found that patients were dissatisfied when they noticed that their physical therapists seemed rushed, which they interpreted as a lack of interest in the patient. In turn, the physical therapists regretted not having enough time to "treat patients to their satisfaction". Potter et al [45], and Hills et al [37], found that many patients felt they did not have enough time to be with their physical therapist, and that the delay for being assigned an appointment was excessive. Some authors have found that patients need more time to discuss certain aspects of their treatment with their physical therapists that they feel unsure of [46]. This demonstrates the importance of establishing joint decision making, one of the 
cornerstones of the PCC, to have enough time for each patient. These findings are consistent with our study and demonstrate the importance of these environmental characteristics for the establishment of the patient-centered therapeutic relationship.

Beattie et al[21), in a study conducted with 1502 patients, found that $71.2 \%$ of those who stated they were fully satisfied with the treatment once it was completed had been treated by a single physical therapist. Subsequently, Medina-Mirapeix et al obtained similar results [47]. These findings are in line with our study, and demonstrate the importance of continuity of care by a single professional for patient satisfaction. In our study it is clear that patients consider this continuity to be a necessary factor in creating a relationship of trust with the physical therapist, which is necessary for the establishment of a good patient-centered Therapeutic Relationship[19,48,49].

Scholl et al [50] carried out a literature search to examine what dimensions make up the concept of PCC. These included the integration of medical and non-medical care, coordination and continuity of care, teamwork and teambuilding. These findings coincide with our study, showing that many of the characteristics of the environment that influence the establishment of a therapeutic relationship of quality are also dimensions of the concept of PCC. This is unsurprising if we consider that the concept of PCC focuses on the characteristics of the relationship between patient and professional as one of the fundamental strategies for its implementation.

Finally, it is worth highlighting an idea that we consider interesting. Some of the characteristics of the environment are difficult to change on behalf of the physical therapist, depending, fundamentally, on the managers of the institution in which he or she works (for example, the high physical therapist/patient ratio). However, many others are directly, fully or partially, the responsibility of the physical therapist. For example, what we have included as social factors: creating a pleasant environment, or being able to create groups of like-minded patients. Moreover, we believe that it is the responsibility of the physical therapist to establish a relationship with the patient in which authenticity, unconditional acceptance, and empathy are paramount, all of which are conveyed by active listening, as characteristics of a high quality therapeutic relationship [51]. This will serve to gain the patient's trust and thus make the patient responsible for his or her own care, which we think would minimize the effects of some of these perceptions (such as lack of autonomy of the professional or lack of coordination among the team, for example). Furthermore, this may facilitate the adjustment of the physical therapist's expectations.

\section{Study limitations}

This study presents several limitations. The retrospective nature of this study may mean that participants' perceptions and experiences have suffered from memory bias. However, the fact that the data was collected simultaneously from several participants, and that, in most cases, several of them were treated by the same physical therapist and at the same center, we believe minimizes this potential problem. Furthermore, the nature of the data collection method (focus groups) may have caused a bias in the form of emotional contagion among participants. However, the fact that the moderator was sufficiently trained to avoid this situation, and the method of analysis, including three independent researchers, were able to mitigate this bias. Finally, given the sample size and the participation of patients, only from some public health centers of the Community of Valencia, these findings cannot be generalized. 


\section{Conclusions}

The physical and organizational characteristics of the environment in which patients receive physical therapy treatment influence their perception of the quality of the therapeutic relationship. These findings add to the existing knowledge relating environmental factors with the perception of quality of the patient-centered therapeutic relationship, and highlight the need for physical therapists and managers to review the environmental factors that may be influencing the relationship from the patient's point of view. This is especially important at a time when patient-centered care is being increasingly implemented. In the future, it would be interesting to study the influence of the environment in private centers, as well as in the treatment of different pathologies, such as neurological or pediatric patients.

\section{Impact on Daily Practice}

The results of this study can be used by managers of centers where physical therapy care is provided to improve aspects that may be creating barriers to the establishment of a patient-centered Therapeutic relathionship. This may in turn improve many of the relevant outcomes of these centers, such as perceived quality or patient satisfaction. Physical therapists can also benefit from these results by understanding the environmental characteristics that can influence these results and, thus, explain to patients the reality of the center from a more genuine point of view, thus increasing patients' trust, and, consequently, strengthening adherence to treatment and joint decision making.

Author Contributions: Conceptualization, Jaume Morera-Balaguer, Mari Carmen Martínez-González, José Martín Botella-Rico and Óscar Rodríguez-Nogueira; Formal analysis, Jaume Morera-Balaguer and Óscar Rodríguez-Nogueira; Investigation, Mari Carmen Martínez-González and Marina Leal-Clavel; Methodology, Jaume Morera-Balaguer, Mari Carmen Martínez-González, Sonia del Río-Medina, Víctor Zamora-Conesa and Óscar Rodríguez-Nogueira; Resources, Sonia del Río-Medina, Víctor Zamora-Conesa, Marina Leal-Clavel and José Martín Botella-Rico; Supervision, Jaume Morera-Balaguer and Mari Carmen Martínez-González. All authors have read and agreed to the published version of the manuscript.

Funding: This research Project was supported by the Programa de Ayuda para Grupos Precompetitivos FUSPSantander from Universidad CEU Cardenal Herrera.

Acknowledgments: We would like to thank the uninterested and essential collaboration of the 31 patients of the following hospitals: General University (Valencia), General University and Vinalopó Hospital (Elche), and the department of health of Denia (Alicante), as well as the managers of these institutions, and finally, we would like to acknowledge the financial support given by the Programa de Ayuda para Grupos Precompetitivos FUSPSantander of the CEU Cardenal Herrera University.

Conflicts of Interest: The authors declare no conflict of interest. 


\section{References}

1. Coats H, Bourget E, Starks H, Lindhorst T, Saiki-Craighill S, Curtis JR, Hays R, Doorenbos A. Nurses' Reflections on Benefits and Challenges of Implementing Family-Centered Care in Pediatric Intensive Care Units. Am J Crit Care. 2018 Jan;27(1):52-58. doi: 10.4037/ajcc2018353. PMID: 29292276; PMCID: PMC5959722.

2. Clay AM, Parsh B. Patient- and Family-Centered Care: It's Not Just for Pediatrics Anymore. AMA J Ethics. 2016 Jan 1;18(1):40-4. doi: 10.1001/journalofethics.2016.18.1.medu3-1601. PMID: 26854635.

3. O'Kane M. Medical homes delivering on promises. Mod Healthc. 2014 Nov 3;44(44):39. PMID: 25509452.

4. Angeli JM, Harpster K, Huijs L, Seid M, Sheehan A, Schwab SM. Patient-Centered Goal Setting in Developmental Therapy: Discordance between Documented Goals and Caregiver-Perceived Goals. Pediatr Qual Saf. 2019 Aug 7;4(4):e199. doi: 10.1097/pq9.0000000000000199. PMID: 31572900; PMCID: PMC6708649.

5. Craig JW, Glick C, Phillips R, Hall SL, Smith J, Browne J. Recommendations for involving the family in developmental care of the NICU baby. J Perinatol. 2015 Dec;35 Suppl 1(Suppl 1):S5-8. doi: 10.1038/jp.2015.142. PMID: 26597804; PMCID: PMC4660048.

6. Smith J, Swallow V, Coyne I. Involving parents in managing their child's long-term condition-a concept synthesis of family-centered care and partnership-in-care. J Pediatr Nurs. 2015 JanFeb;30(1):143-59. doi: 10.1016/j.pedn.2014.10.014. Epub 2014 Oct 24. PMID: 25458112.

7. Coyne I. Families and health-care professionals' perspectives and expectations of family-centred care: hidden expectations and unclear roles. Health Expect. 2015 Oct;18(5):796-808. doi: 10.1111/hex.12104. Epub 2013 Jun 26. PMID: 23800327; PMCID: PMC5060842.

8. Morgan S, Yoder LH. A concept analysis of person-centered care. J Holist Nurs. 2012 Mar;30(1):615. doi: 10.1177/0898010111412189. Epub 2011 Jul 19. PMID: 21772048.

9. Institute of Medicine (US) Committee on Quality of Health Care in America. Crossing the Quality Chasm: A New Health System for the 21st Century. Washington (DC): National Academies Press (US); 2001. PMID: 25057539.

10. Institute for Patient- and Family-Centered Care. Frequently asked questions. http://www.ipfcc.org/faq.html. Accessed November 24, 2019. 42 www.amajournalofethics.org 10.

11. Herrin J, Harris KG, Kenward K, Hines S, Joshi MS, Frosch DL. Patient and family engagement: a survey of US hospital practice [published online ahead of print June 16, 2015]. BMJ Qual Saf. doi:10.1136/bmjqs-2015-004006. 11.

12. COMMITTEE ON HOSPITAL CARE and INSTITUTE FOR PATIENT- AND FAMILYCENTERED CARE. Patient- and family-centered care and the pediatrician's role. Pediatrics. 2012 Feb;129(2):394-404. doi: 10.1542/peds.2011-3084. Epub 2012 Jan 30. PMID: 22291118.

13. American Academy of Pediatrics Committee on Pediatric Emergency Medicine; American College of Emergency Physicians Pediatric Emergency Medicine Committee, O'Malley P, Brown $\mathrm{K}$, Mace SE. Patient- and family-centered care and the role of the emergency physician providing care to a child in the emergency department. Pediatrics. 2006 Nov;118(5):2242-4. doi: 10.1542/peds.2006-2588. PMID: 17079599. 
14. Hartog CS, Bodechtel U. Umgang mit Angehörigen auf der Intensivstation [Family-Centered Care in the ICU]. Dtsch Med Wochenschr. 2018 Jan;143(1):15-20. German. doi: 10.1055/s-0042109257. Epub 2017 Dec 6. PMID: 29212092.

15. Creasy KR, Lutz BJ, Young ME, Stacciarini JM. Clinical Implications of Family-Centered Care in Stroke Rehabilitation. Rehabil Nurs. 2015 Nov-Dec;40(6):349-59. doi: 10.1002/rnj.188. Epub 2015 Feb 3. PMID: 25648522; PMCID: PMC4544639.

16. Newell S, Jordan Z. The patient experience of patient-centered communication with nurses in the hospital setting: a qualitative systematic review protocol. JBI Database System Rev Implement Rep. 2015 Jan;13(1):76-87. doi: 10.11124/jbisrir-2015-1072. PMID: 26447009.

17. An M, Palisano RJ. Family-professional collaboration in pediatric rehabilitation: a practice model. Disabil Rehabil. 2014;36(5):434-40. doi: 10.3109/09638288.2013.797510. Epub 2013 May 29. PMID: 23713990.

18. Hofstede SN, Marang-van de Mheen PJ, Wentink MM, Stiggelbout AM, Vleggeert-Lankamp CL, Vliet Vlieland TP, van Bodegom-Vos L; DISC study group. Barriers and facilitators to implement shared decision making in multidisciplinary sciatica care: a qualitative study. Implement Sci. 2013 Aug 23;8:95. doi: 10.1186/1748-5908-8-95. PMID: 23968140; PMCID: PMC3765956.

19. Hofstede SN, van Bodegom-Vos L, Wentink MM, Vleggeert-Lankamp CL, Vliet Vlieland TP, Marang-van de Mheen PJ; DISC study group. Most important factors for the implementation of shared decision making in sciatica care: ranking among professionals and patients. PLoS One. 2014 Apr 7;9(4):e94176. doi: 10.1371/journal.pone.0094176. PMID: 24710328; PMCID: PMC3978036.

20. Dibbelt S, Schaidhammer M, Fleischer C, Greitemann B. Patient-doctor interaction in rehabilitation: the relationship between perceived interaction quality and long-term treatment results. Patient Educ Couns. 2009 Sep;76(3):328-35.

21. Beattie PF, Pinto MB, Nelson MK, Nelson R. Patient satisfaction with outpatient physical therapy: instrument validation. Phys Ther. 2002 Jun;82(6):557-65. Erratum in: Phys Ther 2002 Aug;82(8):827. PMID: 12036397.

22. Casserley-Feeney SN, Phelan M, Duffy F, Roush S, Cairns MC, Hurley DA. Patient satisfaction with private physiotherapy for musculoskeletal pain. BMC Musculoskelet Disord. 2008 Apr 15;9:50. doi: 10.1186/1471-2474-9-50. PMID: 18412974; PMCID: PMC2359748.

23. Medina-Mirapeix F, Del Baño-Aledo ME, Oliveira-Sousa SL, Escolar-Reina P, Collins SM. How the rehabilitation environment influences patient perception of service quality: a qualitative study. Arch Phys Med Rehabil. 2013 Jun;94(6):1112-7. doi: 10.1016/j.apmr.2012.11.007. Epub 2012 Nov 12. PMID: 23154133.

24. Brady $M K$, Cronin JJ. Some new thoughts on conceptualizing perceived service quality: a hierarchical approach. J Marketing 2001; 65:34-49)

25. Kopec, D. A. (2018). Environmental Psychology for Design. 317. New York: Bloomsbury Publishing Inc.

26. Morera-Balaguer J, Botella-Rico JM, Martínez-González MC, Medina-Mirapeix F, RodríguezNogueira Ó. Physical therapists' perceptions and experiences about barriers and facilitators of therapeutic patient-centred relationships during outpatient rehabilitation: a qualitative study. Braz J Phys Ther. 2018 Nov-Dec;22(6):484-492. doi: 10.1016/j.bjpt.2018.04.003. Epub 2018 Apr 18. PMID: 29705228; PMCID: PMC6235755. 
27. Morera-Balaguer J, Botella-Rico JM, Catalán-Matamoros D, Martínez-Segura OR, Leal-Clavel M, Rodríguez-Nogueira Ó. Patients' experience regarding therapeutic person-centered relationships in physiotherapy services: A qualitative study. Physiother Theory Pract. 2019 Apr 19:1-11. doi: 10.1080/09593985.2019.1603258. Epub ahead of print. PMID: 31002005

28. Del Baño-Aledo ME, Medina-Mirapeix F, Escolar-Reina P, Montilla-Herrador J, Collins SM. Relevant patient perceptions and experiences for evaluating quality of interaction with physiotherapists during outpatient rehabilitation: a qualitative study. Physiotherapy. 2014 Mar;100(1):73-9. doi: 10.1016/j.physio.2013.05.001. Epub 2013 Jun 16. PMID: 23778264.

29. Hill CE, Thompson BJ, Williams EN. A Guide to Conducting Consensual Qualitative Research. The Counseling Psychologist. 1997;25(4):517-572. doi:10.1177/0011000097254001

30. Korsch BM, Gozzi EK, Francis V. Gaps in doctor-patient communication. 1. Doctor-patient interaction and patient satisfaction. Pediatrics. 1968 Nov;42(5):855-71. PMID: 5685370.

31. CRESWELL JW. Research design: qualitative, quantitative, and mixed method approaches. 3rd edition. Los Ángeles: Sage publications; 2009.

32. Escolar-Reina P, Medina-Mirapeix F, Gascón-Cánovas JJ, Montilla-Herrador J, Jimeno-Serrano FJ, de Oliveira Sousa SL, del Baño-Aledo ME, Lomas-Vega R. How do care-provider and home exercise program characteristics affect patient adherence in chronic neck and back pain: a qualitative study. BMC Health Serv Res. 2010 Mar 10;10:60. doi: 10.1186/1472-6963-10-60. PMID: 20219095; PMCID: PMC2847560.

33. Strauss, A., and Corbin, J. (1998). Basics of qualitative research: Techniques and procedures for developing grounded theory (2nd ed.). Thousand Oaks, CA: Sage.

34. Arneill AB, Devlin AS. Perceived quality of care: the influence of the waiting room environment. J Environ Psychol 2002;22:345-60. 21),

35. Keith RA. Patient satisfaction and rehabilitation services. Arch Phys Med Rehabil. 1998 Sep;79(9):1122-8. doi: 10.1016/s0003-9993(98)90182-4. PMID: 9749695.

36. Goldstein MS, Elliott SD, Guccione AA. The development of an instrument to measure satisfaction with physical therapy. Phys Ther. 2000 Sep;80(9):853-63. PMID: 10960933.

37. Hills R, Kitchen S. Satisfaction with outpatient physiotherapy: focus groups to explore the views of patients with acute and chronic musculoskeletal conditions. Physiother Theory Pract. 2007 Jan-Feb;23(1):1-20. doi: 10.1080/09593980601023705. PMID: 17454795.

38. Monnin D, Perneger TV. Scale to measure patient satisfaction with physical therapy. Phys Ther. 2002 Jul;82(7):682-91. PMID: 12088465.

39. Devlin A, Arneill AB. Health care environments and patient outcomes: a review of the literature. Environ Behav 2003;35:665-94.

40. Ulrich RS. Effects of interior design on wellness: theory and recent scientific research. J Health Care Inter Des. 1991;3:97-109. PMID: 10123973.

41. Rubin HR. Status report--an investigation to determine whether the built environment affects patients' medical outcomes. J Healthc Des. 1998;10:11-3. PMID: 10539237.

42. O'Keeffe M, Cullinane P, Hurley J, Leahy I, Bunzli S, O'Sullivan PB, O'Sullivan K. What Influences Patient-Therapist Interactions in Musculoskeletal Physical Therapy? Qualitative Systematic Review and Meta-Synthesis. Phys Ther. 2016 May;96(5):609-22. doi: 10.2522/ptj.20150240. Epub 2015 Oct 1. PMID: 26427530. 
43. Oosterhof B, Dekker JH, Sloots M, Bartels EA, Dekker J. Success or failure of chronic pain rehabilitation: the importance of good interaction - a qualitative study under patients and professionals. Disabil Rehabil. 2014;36(22):1903-10. doi: 10.3109/09638288.2014.881566. Epub 2014 Jan 27. PMID: 24467644.

44. Harrison K, Williams S. Exploring the power balance in physiotherapy. $\mathrm{Br} \mathrm{J}$ TherRehabil.2000;7:355-361.

45. Potter M, Gordon S, Hamer P. The physiotherapy experience in private practice: the patients' perspective. Aust J Physiother. 2003;49(3):195-202. doi: 10.1016/s0004-9514(14)60239-7. PMID: 12952519.

46. Beattie PF, Pinto MB, Nelson MK, Nelson R. Patient satisfaction with outpatient physical therapy: instrument validation. Phys Ther. 2002 Jun;82(6):557-65. Erratum in: Phys Ther 2002 Aug;82(8):827. PMID: 12036397.

47. Medina-Mirapeix F, Oliveira-Sousa SL, Escolar-Reina P, Sobral-Ferreira M, Lillo-Navarro MC, Collins SM. Continuity of care in hospital rehabilitation services: a qualitative insight from inpatients' experience. Braz J Phys Ther. 2017 Mar-Apr;21(2):85-91. doi: 10.1016/j.bjpt.2017.03.002. Epub 2017 Mar 17. PMID: 28460715; PMCID: PMC5537455.

48. Brennan N, Barnes R, Calnan M, Corrigan O, Dieppe P, Entwistle V. Trust in the health-care provider-patient relationship: a systematic mapping review of the evidence base. Int J Qual Health Care. 2013 Dec;25(6):682-8. doi: 10.1093/intqhc/mzt063. Epub 2013 Sep 25. PMID: 24068242.

49. Thom DH, Wong ST, Guzman D, Wu A, Penko J, Miaskowski C, Kushel M. Physician trust in the patient: development and validation of a new measure. Ann Fam Med. 2011 MarApr;9(2):148-54. doi: 10.1370/afm.1224. PMID: 21403142; PMCID: PMC3056863.

50. Scholl I, Zill JM, Härter M, Dirmaier J. An integrative model of patient-centeredness - a systematic review and concept analysis. PLoS One. 2014 Sep 17;9(9):e107828. doi: 10.1371/journal.pone.0107828. PMID: 25229640; PMCID: PMC4168256.

51. Rogers CR. El proceso de convertirse en persona: mi técnica terapéutica. 1a ed. Paidos, editor. Madrid; 2011. 398 p. 